\title{
Belphégor
}

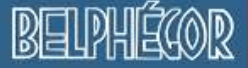

Littérature populaire et culture médiatique

$15-2 \mid 2017$

Middlebrow

\section{Plaisirs et fictions dans la chanson française}

Isabelle Marc

\section{OpenEdition}

\section{Journals}

Electronic version

URL: http://journals.openedition.org/belphegor/997

DOI: 10.4000/belphegor.997

ISSN: 1499-7185

\section{Publisher}

LPCM

\section{Electronic reference}

Isabelle Marc, «Plaisirs et fictions dans la chanson française », Belphégor [Online], 15-2 | 2017, Online since 14 December 2017, connection on 01 May 2019. URL : http://journals.openedition.org/ belphegor/997 ; DOI : 10.4000/belphegor.997

This text was automatically generated on 1 May 2019.

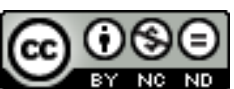

Belphégor est mis à disposition selon les termes de la Licence Creative Commons Attribution - Pas d'Utilisation Commerciale - Pas de Modification 4.0 International. 


\title{
Plaisirs et fictions dans la chanson française
}

\author{
Isabelle Marc
}

1 En France, la culture - sa nature, ses acteurs, ses pratiques, son marché - constitue un enjeu national sur le plan symbolique, politique et économique. La question de la 'culture moyenne' s'avère en conséquence cruciale. En effet, comme le signalent pertinemment Diana Holmes et David Looseley dans un ouvrage récent sur le statut de la culture 'populaire' dans la France contemporaine (Holmes et Looseley 2013 : 230-234), bien que souvent assimilée à la médiocrité ou à la banalité, à une sorte d'arrivisme culturel, la culture moyenne est non seulement appréciée par une majorité de la population mais elle est aussi partiellement légitimée par les institutions. Elle pourrait à ce titre contribuer à concilier la haute culture traditionnelle (exigeante et vraie pour ses partisans, imposée, élitiste et désincarnée pour ses critiques) et la culture populaire (jugée superficielle, standardisée et peu réflexive pour ses détracteurs, authentique et libératrice pour ses défenseurs), surtout dans le contexte des mutations profondes subies par la France au cours des soixante dernières années.

2 À l'instar d'autres genres d'origine populaire, qui ont par la suite été canonisés par le public et par une partie de la critique journalistique et académique - certains genres littéraires, cinématographiques et télévisuels -, la chanson française, notamment celle qui se situerait dans l'héritage de la chanson à textes, la 'bonne' chanson française, constitue l'un des exemples notoires de la culture moyenne en France. Le devenir critique de la chanson, retracé avec acuité par le professeur britannique David Looseley (Looseley 2013a, Looseley 2003), en dit long sur la chanson elle-même, mais aussi sur les enjeux de la culture française en général. À la fois objet culturel et produit commercial, elle a été considérée tantôt comme un 'art véritable' (entendons, légitime, élevé) tantôt comme un 'art mineur', mais aussi comme un 'art moyen' (Bourdieu 1979).

3 En revanche, du point de vue des publics, le succès de la chanson en France est incontestable: les classiques des années 1950-1960, aussi bien auteurs-compositeursinterprètes (ACI) (Brel, Brassens, Ferré, Trenet, Moustaki, Barbara...) que 'simples' interprètes (Piaf, Montand...), font partie du patrimoine culturel national. La popularité 
de leurs successeurs, d'Alain Bashung à Louane en passant par Jean-Jacques Goldman ou Olivia Ruiz, est attestée par leur visibilité médiatique et surtout par la place privilégiée qu'ils occupent sur les listes de meilleures ventes ${ }^{2}$. Aujourd'hui, la chanson jouit de l'attention et souvent aussi de l'estime des médias ainsi que de l'appui des pouvoirs publics (quotas radiophoniques, subventions diverses). Consommée et appréciée par un public très vaste, la chanson se présente ainsi comme un objet protéiforme, hétérogène, aux contours flexibles, aussi bien d'un point de vue stylistique ${ }^{3}$ que d'un point de vue de sa considération critique. Cette absence de caractérisation précise la situe dans un entredeux qui fluctue entre les univers traditionnels de la culture populaire, conçue comme synonyme de la culture de masse, et de la culture élevée ou légitime, un espace symbolique et toutefois réel que nous voulons ici désigner comme culture moyenne. Or, comme nous allons essayer de le démontrer, cet espace ne constitue pas une étape intermédiaire entre les deux pôles sur l'échelle de la légitimité artistique mais possède des caractéristiques qui lui sont propres et qui sont intimement liées à l'éthos contemporain.

4 Le présent travail n'aspire pas à offrir une vision exhaustive de la chanson comme 'art du milieu' par rapport à l'échelle d'évaluation esthétique, mais plutôt à explorer ce qui, dans sa forme et sa configuration, peut faire appel à un public vaste, que l'on pourrait dénommer le public moyen, situé aussi bien entre les extrêmes socioéconomiques qu'entre les goûts et les pratiques culturelles minoritaires ${ }^{4}$. Pour ce faire, nous adopterons une perspective esthétique en donnant en premier une définition du concept de chanson pour en offrir ensuite une vision immanente comme source de plaisir pour l'auditeur moyen en interrogeant les mécanismes expressifs et notamment narratifs de la chanson comme facteur clé de son succès auprès d'un public large et socialement hétérogène.

\section{Définitions}

5 Pour comprendre les enjeux de la chanson en France il convient d'abord de s'interroger sur la polysémie du terme. En effet, d'une part, la chanson est une forme, neutre d'un point de vue idéologique, consistant en une composition brève enregistrée, d'environ trois minutes, faite de mots et de musique, et transposable dans plusieurs langues et cultures (song en anglais, canción en espagnol) ${ }^{5}$. D'autre part, et parallèlement, le terme de chanson fait référence à un genre codifié dans la pratique discursive, celui de la 'chanson française', riche en connotations de tout ordre, comme nous allons le voir, et qui n'a pas toujours d'équivalent dans d'autres aires culturelles (le mot chanson, en italique, est conservé en anglais et souvent en espagnol).

6 En 1979, à partir de données sociologiques datant des années 1960, Pierre Bourdieu décrivait la chanson comme un 'art moyen', la situant ainsi dans l'intermédiaire entre la musique légitime, appréciée par les classes disposant d'un capital culturel supérieur, et la musique de divertissement, consommée par les classes populaires et la petite bourgeoisie. Cet art moyen ne désignait pas la forme chanson en général mais la production de certains artistes (Brassens, Douai) qui proposeraient une sorte de 'poésie populiste' (Bourdieu 1979: 65), perçue par les détenteurs du capital culturel comme plus légitime que celle des chanteurs plus 'populaires' tels que Tino Rossi, Aznavour, Adamo ou Petula Clark. Les constats de Bourdieu attestent du - et contribuent au - processus de légitimation consolidé dans les années 1960, notamment avec l'inclusion d'un certain 
nombre d'auteurs compositeurs interprètes (ACI) dans la collection 'Poètes d'aujourd'hui' puis 'Poésie et chanson' chez l'éditeur Seghers, et qui a consisté d'une part à considérer la chanson comme une évolution de l'histoire littéraire (Canteloube-Ferrieu 1981, Ferrier 2012) et d'autre part comme un survivant de la tradition poétique orale (Zumthor 1983), la situant au-dessus des autres formes de chanson jugées trop divertissantes et/ou trop commerciales, comme le yé-yé. À l'issue de ce processus de légitimation, le genre s'est figé comme synonyme de la 'chanson d'auteur', 'chanson poétique' ou 'chanson à texte'. Pour David Looseley, dans les années 1950-1960 et en lignes générales jusqu'au développement des radios FM, la chanson serait définie par son caractère artisanal, sa volonté artistique et ses aspirations intellectuelles, sa valorisation du direct, la qualité de ses paroles, son ton sincère et sa volonté critique, parfois même didactique, et l'attitude active de son auditoire ('lyrics, critical listening, live performance, creativity and sincerity, and consciousness-raising or even education' (Looseley 2003 : 70). Elle serait donc opposée à la musique commerciale, identifiée en France aux musiques anglo-

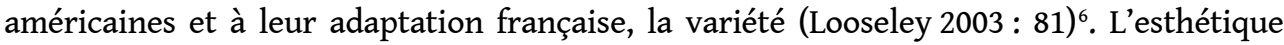
idéaliste de l'auteur serait ainsi greffée sur la chanson, notamment à partir de la figure de l'ACI, omettant tout aspect industriel ou commercial. Dans cette codification, la chanson, bien plus qu'une simple forme, serait devenue un 'produit national authentique', contribuant à la configuration de l'identité française face aux dangers de la modernisation et de l'américanisation.

Or, plus de cinquante ans après l'âge d'or de la 'chanson à texte' et des ACI, les publics, les pratiques musicales et la perception des genres ont logiquement beaucoup évolué. Premièrement, du point de vue des auditeurs, les démarcations sociales et culturelles identifiées par Bourdieu semblent aujourd'hui dépassées, notamment en raison du 'boom musical' (Donnat 2004) survenu grâce à la généralisation des nouvelles technologies de diffusion musicale (hi-fi, baladeurs puis MP3, streaming...) dans la société française et qui a rendu la musique omniprésente dans les instances du quotidien. Ainsi, les distinctions de goût ne correspondent plus à des classes sociales concrètes mais sont plutôt caractérisées par l'éclectisme et l'individualisme :

'Le fait de pouvoir écouter tous les genres de musique possibles, quand on veut et où on veut, a contribué à modifier considérablement le statut des œuvres et la hiérarchie des genres musicaux. Les facilités d'écoute offertes par les progrès technologiques ont permis une relative généralisation des mécanismes de distinction qui, il n'y a pas si longtemps, étaient l'apanage des seuls mélomanes : le fait de personnaliser son univers musical en puisant dans une large palette de goûts est devenu une possibilité offerte à tous.' (Donnat 2004 : 93).

Par ailleurs, il semblerait que la distinction, et donc le capital culturel, se caractérise désormais non plus par l'exclusivité mais par l' 'omnivorité' : les classes les plus éduquées consommeraient toute sorte de produits culturels, y compris les produits autrefois considérés comme populaires ou de masse ${ }^{8}$.

Aux nouvelles conditions matérielles et technologiques, dans les années 1990 s'ajoutent aussi les dispositions légales en vertu desquelles $40 \%$ des musiques radiodiffusées doivent être des musiques d'expression française (Loi n $94-88$ du 1er février 1994). Ces mesures de protection, qui révèlent des enjeux aussi bien idéologiques et identitaires de patrimonialisation que des intérêts économiques, ont pour conséquence une exposition incontournable, volontaire et involontaire, de la majorité de la population à la musique en français. Ceci contribue donc à créer et à consolider un répertoire chansonnier 
national, préservé face à la menace de la musique mondialisée, et auquel le public moyen ${ }^{9}$ peut facilement se référer.

En ce qui concerne les genres les plus appréciés par les publics, en dépit de l'engouement des plus jeunes pour les musiques anglo-américaines dans la décennie précédente (Donnat 2009: 5), on constate aujourd'hui une certaine préférence pour la musique d'expression française, toutes classes sociales confondues, comme le prouvent les listes des meilleures ventes de musique enregistrée en France: en 2014, les dix premières positions sont occupées par des artistes français - ou chantant en français, comme Stromae (Ministère de la Culture 2015) ; en 2015, selon le Syndicat national de l'édition phonographique, 9 des 10 meilleurs ventes reviennent également à des artistes français. En ce sens, le Ministère de la Culture, dans son enquête sur les pratiques culturelles des Français, n'établit pas de différence entre 'chanson française' et 'variété française' ${ }^{10}$. Ainsi s'estompe l'opposition stylistique entre la chanson, patrimoniale et caractérisée comme le segment 'élevé' des musiques 'populaires', et la variété, traditionnellement considérée comme un divertissement purement imitatif des genres étrangers et donc classée en bas de l'échelle de légitimité.

D'un point de vue stylistique, la chanson française de nos jours ${ }^{11}$ s'apparente aussi de plus en plus aux musiques internationales, privilégiant, entre autres, l'expression des émotions, la visibilité du corps et les arrangements riches, face à la littérarité, à l'intellectualisme et à la simplicité instrumentale des ACI classiques (Lebrun 2014). Depuis plus de trente ans, elle se serait donc lancée dans un processus d'hybridation, devenant ainsi un objet protéiforme. En dépit de la persistance de réflexes idéalistes chez certains critiques, David Looseley en conclut que le genre chanson ne posséderait plus de caractéristiques esthétiques propres mais qu'elle serait devenue un discours idéologique, basé sur l'identité nationale, par voie de conséquence, différentiée des musiques d'origine étrangère (Looseley 2013a : 81).

La chanson ne serait donc plus seulement la musique de Brassens et Barbara, mais aussi celle d'Étienne Daho et de Zaz, de Louis Attack et d'Abd al Malik. Catégorie hétérogène, postmoderne et liquide, la chanson serait aujourd'hui définie par sa francité, cette francité qui se construit, précisément et surtout, sur l'emploi de la langue française, comme élément fédérateur des différents styles et des différentes époques et qui se situe au cœur-même de sa production et de sa réception. Comme le signale la musicologique Catherine Rudent :

'C'est seulement de manière très partielle et peut-être secondaire qu'une spécificité française peut être remarquée : ainsi, l'utilisation de la langue française induirait une certaine manière d'enregistrer [...] il y aurait une place française faite au texte. [...] il semble que le genre chanson, aussi éclectique qu'il soit et indépendamment des styles musicaux qu'il utilise, pose la parole (et les paroles) en point focal, non seulement sur le plan de la valeur et du sens [...] mais aussi sur le plan sonore : la prononciation, les inflexions vocales et leur appropriation au sens des paroles sont déterminants dans l'évaluation de leur travail par les différents acteurs [de l'album].' (Rudent 2011 : 250-251).

13 Ainsi, musicalement hétérogène, mais idéologiquement marquée comme produit national face aux musiques étrangères, ayant dépassé pour la plupart les préjugés esthétiques de différentiation identifiés par Bourdieu, la chanson en France se définit par l'emploi 'central', 'focal' de la langue française ${ }^{12}$, qui la caractérise par ailleurs comme un produit compréhensible et reconnaissable au sein de la communauté linguistique et culturelle. Par ailleurs, grâce aux stratégies de diffusion et de commercialisation mais aussi au 
soutien des pouvoirs publics, elle est consommée activement ou passivement par un public vaste et sociologiquement hétérogène. Elle est donc légitimement située au cœur de la société française, dans son noyau 'banal', entendu ici comme 'ce qui est commun, qui est à la disposition de tout le monde' (Trésor de la Langue Française informatisé), disponible partout et compréhensible par tous. À partir de cette définition, nous nous proposons maintenant d'interroger la chanson en tant que forme immanente, afin d'expliquer pourquoi elle est à la fois une source de plaisir esthétique individuel et une forme culturelle patrimoniale.

\section{Esthétique de la chanson française}

Les lignes qui suivent ont pour objectif de présenter les caractéristiques esthétiques de la chanson française. Cette caractérisation nous permettra d'examiner le rapport entre l'esthétique et la réception de la chanson et de comprendre sa spécificité par rapport à d'autres formes de 'musique actuelle' et à d'autres objets de la culture contemporaine.

Le premier facteur de succès d'une chanson concerne, très probablement, ses aspects musicaux, à savoir, la mélodie, l'harmonie, les arrangements ainsi que la voix de l'interprète: il s'agit souvent d'une savante - ou chanceuse - combinaison entre le fameux hook anglais, ce que Peter Szendy dénomme la 'puissance d'accroc' (Szendy, 2008: 47), les arrangements justes, confirmant ou défiant le style musical dans lequel s'inscrit le morceau, et la performance de l'interprète. À ceci s'ajoutent, bien évidemment, l'ensemble des facteurs 'externes' liés à la promotion, à l'image de l'artiste, à la configuration du marché, etc. Laissant de côté les aspects musicologiques et sociologiques qui dépassent l'objet du présent travail, nous nous concentrerons sur quelques-uns de traits marquants de la chanson sur le plan de sa structure et ses fonctions esthétiques en privilégiant le point de vue du récepteur.

La forme chanson est, comme on l'a vu, définie par une durée limitée, d'environ trois minutes. Imposée par les techniques d'enregistrement à ses débuts, cette contrainte temporelle s'est ensuite constituée en caractéristique du genre. Ainsi, l'économie musicale, mais aussi la création et l'écoute des chansons sont basées sur cette restriction temporelle : sur le plan de la création, le petit format impose, entre autres, concision et intensité; sur le plan de la réception, il permet aux chansons de s'enchaîner, d'être identifiables rapidement, mais aussi d'être interchangeables sur les différents modes de diffusion. En conséquence, l'auditeur peut apprécier une chanson de façon immédiate, à tout moment et dans pratiquement toute circonstance. Cette accessibilité, cette facilité d'approche, cette ambition que l'on pourrait qualifier de modeste, différencie la chanson des œuvres artistiques à volonté totalisante, telles que l'opéra ou le roman, qui se déroulent et qui exigent le temps long. La brièveté constitue donc une condition pour la popularité, favorisant la démocratisation de l'expérience musicale, à la manière du livre de poche ${ }^{13}$ dans le domaine littéraire. Par ailleurs, la brièveté facilite la mémorisation ou du moins une reconnaissance relativement aisée du morceau. Il est impossible - ou peu probable - de mémoriser un roman, tout au plus un poème court, alors que tout un chacun peut apprendre une chanson.

Si la chanson est brève, elle est aussi répétitive ; certes, toute forme musicale est basée sur la répétition mais la chanson l'est d'autant plus que sa structure se construit systématiquement sur des 'effets de récurrence' (Hirschi 2008: 37), notamment sur 
l'alternance entre couplets et refrain ${ }^{14}$. Sur le plan verbal, la répétition est liée aux origines orales et aux procédés mnémotechniques lyriques de la forme chanson, mais elle est aussi façonnée par les conventions du genre musical qu'elle cultive. Ainsi, certains genres (hard rock, électro, mais aussi chansons pour enfants) sont souvent définis par les effets d' 'incantation' provoqués par la répétition, où le sujet qui écoute semble s'abandonner à une sorte de transe. À cette jouissance physique et psychique plus ou moins inconsciente, mais aussi culturelle, s'ajoute la participation active du sujet dans son écoute. Ainsi, lorsqu'un auditeur écoute pour la première fois une chanson, il ${ }^{15}$ anticipe sa syntaxe répétitive. Cette qualité, que l'on pourrait qualifier d'auto-prédictive, contribue à la jouissance de l'auditeur. C'est pourquoi, en écoutant une chanson, d'autant plus si nous la connaissons, nous anticipons ce qui va suivre; nous pouvons même chanter, mentalement ou de vive voix, le refrain que nous connaissons par cœur ou que nous venons de découvrir. Nous éprouvons donc le plaisir de la participation, de l'intersubjectivité. Dans les mots d'Elena Hellmuth Margulis, la répétition 'encourages embodiment. And this embodiment contributes to musical pleasure' (Hellmuth Margulis 2013 : 12). Ici, l'expérience esthétique n'est pas détachée de l'objet mais y participe, et devient, en quelque sorte, poiesis, création.

En outre, la chanson est répétée, potentiellement ad libitum et ad infinitum. En tant que produit de consommation de masse, elle est vouée à être écoutée autant de fois que possible, générant à la fois des revenus pour ses détenteurs de droits et le plaisir de la reconnaissance pour ses auditeurs. Réécouter, c'est jouir à nouveau ce qu'on a aimé dans le passé, c'est aussi anticiper, retrouver, revenir. Or, si la chanson reste invariable, notre perception, elle, change à chaque écoute, portée par notre devenir inéluctable. Et c'est alors que surgit, si souvent, la nostalgie, invoquée par le 'signe mémoratif' qu'est la musique (Rousseau, $1768: 314$ ). Nous avons analysé ailleurs les ressorts de la nostalgie dans la chanson française, notamment chez Brassens et chez Aznavour (Marc 2012, Marc 2014), mais il convient ici de rappeler comment la chanson déclenche la mémoire de l'auditeur : premièrement, la chanson évoque sa forme elle-même - on se souvient des paroles, de la mélodie, de la performance; deuxièmement, elle rappelle la mémoire culturelle et esthétique dans laquelle elle s'inscrit, c'est-à-dire, les autres chansons, les autres textes qui conforment le patrimoine culturel, à la fois individuel et partagé, de l'auditeur ; troisièmement, elle déclenche la mémoire individuelle : l'auditeur remémore de façon volontaire, en décidant d'écouter tel ou tel morceau, le vécu lié à cette chanson ; finalement, la chanson précipite l'anamnèse involontaire, le jaillissement du souvenir inattendu. À cet égard, le philosophe Peter Szendy explore les effets des tubes, ces vers d'oreille qui surgissent ou resurgissent de façon récurrente dans notre psyché à la manière d'hymnes subjectifs, participant à la fois du banal et de l'absolument intime inthymnité (Szendy 2008: 76). Ceci nous porte à la question fondamentale de l'auditeur individuel qui, par son expérience unique, non-interchangeable - contrairement aux chansons - transforme le banal en irremplaçable, le collectif en subjectivité irréductible et sur laquelle nous reviendrons plus avant.

19 La chanson (song) est donc une forme brève, répétitive et répétée, sollicitant de ce fait la mémoire de l'auditeur. Cette caractérisation est valable pour l'ensemble des musiques actuelles. Mais la chanson est aussi un texte verbal interprété par une voix qui aspire à communiquer un message référentiel, et c'est précisément sur ce point que se trouve vraisemblablement la spécificité de la chanson française. En effet, on a beaucoup écrit sur le statut des paroles des musiques populaires : pour certains elles seraient insignifiantes 
(ou presque) - critique anglophone surtout - alors que pour d'autres - critique française, notamment dans le cas des ACI - elles constituent l'essence de la chanson ${ }^{16}$. Que l'on accorde ou non un statut central aux paroles, que l'auditeur y prête attention ou non de façon systématique, dans le cas de la chanson française, comme on l'avançait dans la première section de ce travail, il est certain qu'elles occupent une place prépondérante (Looseley 2003, Hawkins 2000), constituant une de ses spécificités par rapport à la musique populaire en anglais (global pop-rock). Ainsi, pour les francophones, la chanson d'expression française aurait quelque chose à dire, ses paroles seraient signifiantes. C'est ainsi que le répertoire de la chanson des $\mathrm{XX}^{\mathrm{e}}$ et $\mathrm{XXI}^{\mathrm{e}}$ siècles, du 'Gorille' de Brassens jusqu'à 'La fille de l'Est' d'Arthur H, en passant par 'Nantes' de Barbara, regorge de textes mémorables, de fictions habitées par des personnages et des histoires qui véhiculent des émotions mais aussi des visions du monde, des idéologies, qui ont parfois acquis le statut de mythes populaires contemporains. Effectivement, au-delà des questions patrimoniales identitaires, il est vrai que, dans le cas de la chanson française, on (re-)connaît les paroles, on s'en souvient, comme on se souvient de l'air et de la voix qui les chante. Or, pourquoi accorde-t-on autant d'importance à ces textes ? Pourquoi sont-ils mémorables à ce point ?

Prenons comme exemple deux morceaux créés par des artistes français mais que rien ne rapproche à l'exception de leur immense succès national et international : 'La bohème' de Charles Aznavour (1965) ${ }^{17}$ et 'Get Lucky' de Daft Punk, interprété par l'Américain Pharrell Williams ${ }^{18}$ (2013). Les paroles de 'La bohème' - son récit, ses personnages - sont gravées dans la mémoire de plusieurs générations alors que dans 'Get Lucky', tube certes très récent, les paroles jouent un rôle secondaire. Plusieurs raisons sont à l'origine de cette asymétrie dans le statut du texte verbal: tout d'abord, 'La bohème' est chantée en français alors que 'Get Lucky' l'est en anglais. Ce qui pourrait paraître une lapalissade s'avère en réalité fondamental pour comprendre les enjeux de la langue dans l'écoute des musiques populaires. En effet, la langue maternelle (ou d'adoption) détermine ce que nous écoutons et la façon dont nous l'écoutons: nous sommes attachés et nous mémorisons ce que nous comprenons. Ainsi, chez les francophones, le plaisir lié à l'écoute de la chanson ne peut pas être dissocié de sa compréhension. Il s'agit donc d'un plaisir vernaculaire, différent de celui que l'on éprouve lorsqu'on écoute une chanson (song) dont ne nous saisissons pas, ou peu, le sens linguistique ${ }^{19}$. Deuxièmement, la prégnance des paroles de 'La bohème' est liée à des raisons d'ordre cognitif et esthétique. En effet, il est probable que l'on s'attache davantage aux mots chantés par Aznavour parce qu'ils nous proposent un monde fictionnel, où des personnages, décrits avec un certain degré de détail, évoluent au fil d'un récit, activant ainsi l'immersion mimétique. À contrario, dans 'Get Lucky', il n'y a ni récit d'événements ni personnages caractérisés. En définitive, ces deux titres procurent un plaisir esthétique différent. 'Get Lucky' active la jouissance musicale, non-référentielle, privilégiant la réponse sensible, 'émotionnelle' et 'somatique'. 'La bohème', de son côté, est liée au plaisir musical, certes, mais aussi au plaisir référentiel de l'immersion fictionnelle, au plaisir que tout un chacun peut éprouver en écoutant une histoire 'bien' racontée. Le contraste entre ces deux tubes, en dépit de leur origine française commune, nous permet de confirmer que le genre 'chanson française' est caractérisé non pas par la nationalité des artistes ou de la production, mais par la centralité des paroles - du sens référentiel - face aux 'autres' types de musiques actuelles, liées à la tradition anglo-américaine, majoritaires sur la scène internationale, et davantage caractérisées par des réponses somatiques, largement détachées de sens référentiel, chez leur public. 
21 Par ailleurs, et en dépit des risques de généralisation, un regard d'ensemble sur la chanson française, chantée en français, des $\mathrm{XX}^{\mathrm{e}}$ et $\mathrm{XXI}{ }^{\mathrm{e}}$ siècles, certes vaste et protéiforme, nous permet de discerner davantage de chansons racontant une histoire située dans le passé - chanson à dominante narrative -, comme 'La bohème', que des textes exprimant un état ou une émotion - chanson à dominante lyrique -, comme ' $Y$ 'a d'la joie'20, un des tubes emblématiques de Charles Trenet (1938). En ce sens, Simon Frith affirme que la chanson française est 'the most obvious narrative song' (Frith 1996 : 170), opposée aux songs de la tradition britannique, plus ironiques, et de la tradition afroaméricaine, plus émotionnelles (Frith 1996 : 170-171) ${ }^{21}$. David Looseley abonde dans cette idée et analyse comment le répertoire d'Édith Piaf constitue un exemple révélateur de cette dominante narrative, construite non seulement à partir du texte verbal mais aussi à partir de la mélodie et de la performance de l'artiste (Looseley 2013b : 234-246). Pour notre part, nous constatons aussi cette tendance à la narrativité, combinée certes à d'autres fonctions expressives. Il serait souhaitable de confirmer cette intuition en réalisant des analyses par genre, par période, voire par artiste ; nous nous contenterons ici d'offrir quelques réflexions générales sur les enjeux de la fiction dans la réception chez l'auditeur moyen.

Les histoires que nous racontent les chansons sont forcément brèves. Il s'agit de microfictions caractérisées par la densité de l'expression, basée sur l'économie verbale. En effet, quelques centaines de mots suffisent à créer des univers narratifs, des tranches de vie possédant une entité esthétique et fictionnelle capable de s'inscrire dans l'imaginaire individuel et collectif de façon perdurable. Chacun, selon son âge et ses préférences, possède son propre panthéon de personnages chantés: la bonté de l'Auvergnat (Brassens), les malheurs de Jim (Souchon), le charme de l'Aziza (Balavoine), la jeunesse de Melody Nelson (Gainsbourg)... parmi tant d'autres; on se rappelle les histoires d'amour et de désamour interprétées par Brel, par Dalida, par Adamo, par Gréco, par Hardy, qui configurent d'ailleurs une bonne partie de l'éducation sentimentale des Français, tout comme les épopées canailles de Renaud, les récits décalées de Gainsbourg, les petites histoires quotidiennes de Delerm, les joies et les misères intimes de Biolay, les fantaisies décalées d'Olivia Ruiz. Et ce, il nous semble, avec autant de force sinon plus que les 'aventures' d'un Julien Sorel, d'une Emma, d'un Rastignac, d'un Marcel.

Où réside donc l'emprise des personnages et des univers fictionnels de la chanson ? Il y a, tout d'abord, des raisons d'ordre anthropologique que partagent toutes les formes des arts fictionnels: nous sommes l' 'espèce fabulatrice' (Huston 2008: 29-30), nous nous construisons, nous-mêmes et notre monde, au moyen de représentations fictionnelles. Pour Jean-Marie Schaeffer, suivant Aristote, si la nature de la fiction est cognitive, sa fonction primordiale est d'ordre hédonique (Schaeffer 1999 : 318-319). Nous créons, nous regardons, nous lisons et nous écoutons des fictions parce qu'elles nous procurent du plaisir, le plaisir de l'immersion fictionnelle qui nous permet de nous détacher de la réalité, de faire 'comme si' on se retrouvait dans la situation posée par la fiction, cessant d'être nous-mêmes le temps du récit, 'introduisant ainsi une distance de nous-mêmes à nous-mêmes' (Schaeffer 1999 : 325). Si la fiction est le principal mode de représentation esthétique, le moyen privilégié de modéliser le monde sans visée pragmatique (id.), l'on comprend alors que lorsqu'une chanson véhicule un récit, celle-ci soit appréhendée par l'imagination - la représentation - esthétique et donc aussi par la mémoire de la représentation. Les chansons à dominante narrative participent donc de ce plaisir immanent de la fiction. 
ais, ce plaisir général de l'immersion fictionnelle est conditionné par l'agencement interne de la fiction, qui doit en conséquence être 'bien' racontée. Le critère de qualité narrative est certes extrêmement complexe et contingent et ne peut être posé à priori ; seule l'analyse des récits permet, à posteriori, de constater que telle ou telle formule narrative a bien fonctionné auprès d'un public déterminé. Comme on l'a déjà signalé, les fictions de la chanson française ont rencontré un succès important chez les auditeurs francophones - ailleurs aussi, mais les raisons en sont forcément différentes -; ses histoires semblent donc avoir été 'bien' posées. Voyons maintenant les caractéristiques qui à notre sens fondent ce plaisir.

Dans leur analyse des fictions courtes ou microfictions dans la littérature française à partir des années 1980, Dominique Rabaté et Pierre Schoentjes affirment que dans ces formes brèves,

'quelque chose se referme aussitôt, interdisant le développement, le frappant du sceau d'une banalité connue d'avance. Le code, activé par le lecteur [ici, l'auditeur] en même temps qu'il lit [écoute], joue à plein régime pour remplir les blancs du texte, pour les saturer presque par avance. La vitesse fonctionne grâce à cette complicité qui est l'une des forces de la microfiction quand elle réussit. Au lieu du roman attendu, au lieu d'en faire toute une histoire comme dit si bien la langue commune, une sorte de politesse retenue accélère tout le déroulement prévisible. Jusqu'à la chute qui peut, en un ultime sursaut, en retourner le sens in extremis.' (Rabaté et Schoentjes $2010: 7$ )

Si l'on remplace le terme 'lecteur' par celui d' 'auditeur', cette définition semble s'adapter parfaitement à notre objet. En effet, comme on l'a vu, un des plaisirs de la chanson est lié à l'anticipation : puisqu'une chanson est, par nature, écoutée plusieurs fois, puisque ses codes culturels et stylistiques sont prévisibles, l'auditeur prévoit ce qui va se passer, musicalement et verbalement. Par ailleurs, sa brièveté temporelle et sa concision verbale, basée sur des ellipses de tout ordre, contribuent également à son ouverture, au silence référentiel nécessaire pour que l'auditeur puisse en combler les lacunes, activant ainsi son imagination et son activité créatrice ${ }^{22}$. À cet égard, Marielle Macé, explorant les interactions entre la lecture littéraire et la vie, identifie, entre autres, la capacité de la lecture pour faire 'infléchir' nos perceptions. Ainsi, par exemple, reprenant Barthes qui à son tour commente Proust (Macé 2011a : 40 et suivantes), elle évoque le geste consistant à 'lever la tête' en lisant, pour réfléchir ou songer à ce que nous lisons, portés par l'attention intense que suscite le texte. Nous pouvons aussi lever la tête, pour, tout en écoutant, penser, sentir, nous souvenir. Et aussi pour nous livrer à la rêverie du 'comme si', accentuée précisément par la concision de la chanson. En levant la tête (les oreilles), nous suspendons notre écoute linéaire, tout en entendant, et nous pouvons prolonger les histoires qui ne sont qu'amorcées dans la chanson, complétant cette tranche de vie qui est posée, comme un seuil, comme un début de toute une histoire qui n'est qu'aperçue et qu'il nous est donné d'accompagner. La chanson ne reproduit pas une agonie - même si sa structure est orientée vers une fin toute proche, comme l'affirme Stéphane Hirschi (Hirschi 2008: 33) -, mais au contraire une ouverture vers une histoire esquissée, qui n'est pas la nôtre mais que nous nous approprions, et que nous pouvons, à loisir, continuer, couper, répéter, oublier aussitôt ou récupérer à tout moment.

Le répertoire de la chanson française - dès son apparition en tant que musique enregistrée jusqu'à nos jours - nous offre des micro-récits extrêmement variés et disponibles à souhait, parmi lesquels nous pouvons retrouver des drames quotidiens (Aznavour, Delerm...), des mélodrames (Christophe, Dassin...), des tragédies (Brel, Ferré,

Belphégor, 15-2 | 2017 
Barbara...), des distractions ludiques (Gainsbourg, Daho, Ruiz...), des hallucinations (Dominique A, Camille...), des provocations (Vian, Fontaine..), des incitations érotiques (Polnareff, Gréco...), des critiques sociales (Brassens, Abd al Malik...). Ces histoires à peine esquissées mais dont la prégnance sur l'imaginaire est connue de tout un chacun ne se renferment pas sur elles-mêmes, mais au contraire s'ouvrent autant sur le collectif que sur l'individuel, sur le social que sur le subjectif. En effet, si 'la vie affective y nourrit son intensité d'un corps à corps avec l'appauvrissement' (Macé 2011b : 770), les fictions de la chanson française, brèves, modestes, souvent aussi formulaires, confèrent à l'auditeur francophone le loisir du flâneur qui les consomme en se laissant prendre au jeu de la marchandise, mais qui peut aussi les manipuler (Szendy 2008 : 22), les interpréter, les compléter à sa guise. Ainsi, de l'interchangeable surgit le spécifiquement individuel, le plus radicalement exclusif et précieux de l'expérience individuelle.

\section{Conclusion}

En dépit de quelques exceptions, la culture contemporaine ne semble plus pouvoir être conçue selon le schéma classique opposant le populaire - le corps, le divertissement, la facilité, la standardisation, le peuple - et l'élevé - l'esprit, l'exigence, la pureté, l'individu. Aujourd'hui, tous ces attributs se confondent et s'entremêlent dans les pratiques culturelles (création, diffusion, consommation). C'est pourquoi, en dépit des relents conservateurs d'une partie de la critique, il nous semble nécessaire de sortir de ce binarisme traditionnel pour trouver une nouvelle catégorisation favorisant des approches qui permettent de mieux appréhender les formes culturelles de notre temps et les plaisirs esthétiques qu'elles nous procurent. C'est alors que le concept de culture moyenne peut nous aider à sortir de l'impasse idéaliste et à rendre compte des phénomènes culturels contemporains. En effet, l'expression culture moyenne ne fait pas pour nous référence à un espace plus ou moins amorphe où viendraient s'échouer des œuvres ne pouvant être classées ni dans le populaire ni dans le savant. Au contraire, la culture moyenne aujourd'hui désigne le champ des objets qui, par leurs moyens de création et de diffusion aussi bien que par leur structure immanente, font appel à et sont consommés par un public majoritaire ${ }^{23}$. Ce public, bien qu'il soit souvent localisé dans les classes moyennes ${ }^{24}$, peut être caractérisé comme sociologiquement hétérogène, et affiche des goûts et des pratiques culturels éclectiques. Le dépassement du binarisme savant-populaire tient ainsi à la configuration des œuvres elles-mêmes (esthétique, symbolique, idéologique), aux moyens de production et de distribution, mais aussi à la reconnaissance de la part des instances de légitimation (critique journalistique et universitaire) de bon nombre de manifestations culturelles autrefois considérées comme populaires et aujourd'hui perçues comme légitimes. En ce sens, la culture 'populaire / de masse' et la culture 'élevée / savante' se voient progressivement redéfinies, déplacées, limitées, voire neutralisées par la culture 'moyenne', majoritaire économiquement et sociologiquement, et légitimée de surcroît par les publics et par la critique. En outre, suivant la logique régnante du système de production culturelle capitaliste, ces objets sont eux-mêmes majoritaires sur le marché : les artistes et les industries culturelles visent, pour la plupart, à atteindre le plus grand nombre, ce qui les mène à produire des œuvres susceptibles de plaire à des publics très variés. Suivant cette logique, le champ culturel contemporain recherche à la fois le général et les niches de marché, tentant ainsi d'assurer la diversité sur le plan esthétique et commercial. Il est important de signaler en ce sens que ce qui pourrait sembler une 
actualisation ou une victoire de la culture de masse sur toute autre catégorie plus exigeante constitue plutôt une nouvelle étape dans la configuration, la perception et la consommation des produits culturels, liée indéfectiblement aux nouvelles conditions socio-économiques de notre temps, et qui ne saurait être expliquée ni esthétiquement ni sociologiquement par les catégories précédentes.

29 La chanson fait partie intégrante de cette culture moyenne actuelle dans le contexte français: hybride et protéiforme d'un point de vue stylistique, définie par la place centrale réservée aux paroles et à l'emploi de la langue française, il s'agit à ce jour de la musique préférée des Français. Ce succès tient à des facteurs externes - industrie du disque, politiques culturelles - mais aussi et surtout, comme nous avons essayé de le démontrer, aux plaisirs esthétiques qu'elle procure à ses auditeurs et qu'il nous semble impossible d'expliquer en appliquant la dichotomie classique.

En effet, la chanson est un jeu fictionnel, une petite chose qui ne dure que trois minutes, un objet de consommation banal, à la portée de tous, qui ne requiert que très peu d'efforts pour être appréhendé. Il s'agit donc d'une forme artistique spécialement apte au succès dans le monde contemporain marqué par la vitesse et le mouvement constant. Pour autant, elle contient en elle la source de plaisirs non négligeables, comme on l'a vu dans la deuxième section de ce travail consacrée à son esthétique : le plaisir musical ${ }^{25}$, souvent aussi le plaisir de l'immersion mimétique, auxquels s'ajoutent le plaisir mémoriel et le plaisir de la jouissance partagée. Ainsi, les chansons, avec leurs airs accrocheurs et leurs fictions brèves, constituent des objets à la fois sensibles et intelligibles, et sont d'autant plus acceptables pour le public majoritaire contemporain qu'elles sont 'faciles' et accessibles. Une grande part de leur attrait consiste donc à combiner ces deux formes de jouissance esthétique, complémentaires et inséparables, mais où toutefois les paroles, le logos si cher à la culture française, jouent un rôle central.

31 Le plaisir mémoriel, de son côté, est invoqué par la chanson dans son unité (musique, parole, performance), dans ses réitérations et ses resurgissements. Comme le décrit si bien la Recherche, l'art - ici, la chanson - déclenche, entre autres, la mémoire individuelle involontaire, permettant à l'individu de retrouver l'essence de son passé. Mais en tant que produit de consommation majoritaire, la chanson possède aussi une dimension collective. En effet, l'exposition volontaire et involontaire du public aux chansons, soutenue par l'État et promue par l'industrie, les situe au cœur de l'imaginaire collectif. Dans la chanson nous trouvons donc les enjeux de l'expérience esthétique individuelle, unique, irréductible - ma mémoire, mon devenir - et de l'expérience collective, culturelle - celle de mes amis, mes voisins, mes compatriotes, qui reconnaissent telle ou telle chanson, au-delà des communautés esthétiques et des sous-cultures. Le 'je' et le 'nous' ou encore le 'je' et l' 'autre' s'unissent dans l'expérience du jeu de la chanson, investie alors de la catégorie de 'lieu de mémoire'. Il s'agit donc d'une expérience partagée, modeste et riche à la fois, dont seuls les usages peuvent être triviaux, où les plaisirs de la musique se voient redoublés par les plaisirs de la fiction. Dans l'ère de l'immédiateté, de la portabilité, des flux incessants, la chanson, par son esthétique concise, allusive et ouverte, par sa malléabilité et son hybridité, par son rapport flexible aux genres musicaux et aux diverses manifestations artistiques, tout en restant fortement ancrée dans l'imaginaire collectif et la culture vernaculaire, semble aujourd'hui s'ériger en paradigme de la culture moyenne, majoritaire, en France. 


\section{BIBLIOGRAPHY}

Astor, Pete, 'The poetry of rock : song lyrics are not poems but the words still matter ; another look at Richard Goldstein's collection of rock lyrics', Popular Music, 29 (1), 2010, 143-148.

Bourdieu, Pierre, La distinction. Critique sociale du jugement, Paris, Les Éditions de Minuit, 1979. Cantaloube-Ferrieu, Lucienne. Chansons et poésie des années 30 aux années 60. Paris, Nizet, 1981. Coulangeon, Philippe, 'I. Pratiques culturelles et stratification sociale', Sociologie des pratiques culturelles, Paris, La Découverte, « Repères », 2010, en ligne : www.cairn.info/sociologie-despratiques-culturelles--9782707164988-page-5.htm.

Donnat, Olivier, 'Les pratiques culturelles des Français à l'ère numérique', Culture Études, Paris, Ministère de la Culture et de l'Éducation, 2009.

Donnat, Olivier, 'Les univers culturels des Français', Sociologie et sociétés, Volume 36, numéro 1, printemps 2004, 87-103.

Ferrier, Michaël, 'Pays profond de l'ouïe', dans Stéphane Audeguy et Philippe Forest (éds.), Variétés : littérature et chanson, Nouvelle Revue Française, no 601, juin 2012, 32-40.

Frith, Simon, 'Why Do Words Have Songs', dans Levin White, (éd.), Lost in Music : Culture. Style and the Musical Event, London and New York : Routledge, 1987, 77-106.

Frith, Simon, Performing Rites. Evaluating Popular Music, Oxford, Oxford University Press, 1996.

Griffiths, Dai, 'From Lyrics to Anti-Lyrics : analyzing the words in pop songs' dans Alan Moore (éd.), Analyzing Popular Music, Cambridge, Cambridge University Press, 2003, 39-50.

Hawkins, Peter, Chanson : the French singer-songwriter from Aristide Bruant to the present day, Aldershot, Ashgate, 2000.

Hellmutt Margulis, Elisabeth, On Repeat : How Music Plays The Mind, Oxford, Oxford University Press, 2013.

Hirschi, Stéphane, Chanson. L'art de fixer l'air du temps - de Béranger à Mano Solo, Valenciennes, Presses Universitaires de Valencienne, coll. Les Belles Lettres, 2008.

Holmes, Diana et Looseley, David (eds.), Imagining the popular in contemporary French culture, Manchester \& New York, Manchester University Press, 2013.

Huston, Nancy, L'espèce fabulatrice, Arles, Actes Sud, coll. Un endroit où aller, 2008.

Lebrun, Barbara, 'Beyond Brassens : Twenty-First Century Chanson and the New Generation of Singer-Songwriters', Modern \& Contemporary France, 22 :2, 2014, 159-175.

Looseley, David, Popular Music in Contemporary France : Authenticity, Politics, Debate, Oxford et New York, Berg, 2003.

Looseley, David, 'Authenticity and appropriation : a discursive history of French Popular Music', dans Diana Holmes et David Looseley (eds.), Imagining the popular in contemporary French culture, Manchester \& New York, Manchester University Press, 2013a, 47-84.

Looseley, David, 'Finding the Plot in French Chanson :

Édith Piaf and the Narrative Song', dans Diana Holmes, David Platten, Loïc, Artiaga, et Migozzi, 
Jacques (éds.), Finding the Plot : Storytelling in Popular Fictions, Cambridge, Cambridge Scholar Publishing, 2013b, 234-246.

Marc, Isabelle, 'Aznavour ou le drame nostalgique populaire', Volume !, 11 : 1, 2014, 55-67.

Marc, Isabelle, 'How do we listen to popular music in Europe?', Journal of European Popular Culture, Vol 4. (1), 2013, 29-35.

Marc, Isabelle, 'Une France passéiste ? La nostalgie comme motif esthétique et thématique chez Georges Brassens', French Cultural Studies, vol. 23, n 3, 2012, 239-255.

Marc, Isabelle, 'De la poésie avant toute chose : pour une approche textuelle des musiques amplifiées'. Synergies Espagne, vol. 4, 2011, 51-61.

Macé, Marielle, Façons de lire, manières d'être, Paris, Gallimard, NRF Essais, 2011a.

Macé, Marielle, 'La bande-son de l'existence', Critique 2011/10 (n 773), 2011b, 762-774.

Middleton, Richard, 'In the Groove or Blowing your Mind? The pleasures of musical repetition', dans Andy Bennet, Barry Shank et Jason Toynbee (éds.), The Popular Music Studies Reader, Oxon and New York, 2006, 15-20.

Ministère de la Culture, 'Médias et industries culturelles', Chiffres clés, statistiques de la culture et de la communication 2016, Paris, Ministère de la Culture - DEPS, Chiffres clés statistiques de la culture, 2016. En ligne : www.cairn.info/chiffres-cles-statistiques-de-la-culture-2016--9782111281585page-169.htm.

Peterson, Richard A. 'Le passage à des goûts omnivores : notions, faits et perspectives', Sociologie et sociétés, Volume 36, numéro 1, printemps 2004, 145-164.

Rabaté, Dominique et Schoentjes, Pierre, 'Micro-scopies', Revue critique de fixxion française contemporaine, $\mathrm{n}^{\circ} 1,2010,1-10$. En ligne : http://www.revue-critique-de-fixxion-francaisecontemporaine.org/rcffc/article/view/fx01.01/186

Rousseau Jean-Jacques, Dictionnaire de la musique, Paris, Chez la Veuve Duchesne. 1768.

Rudent, Catherine, L'album de chansons. Entre processus social et œuvre musicale. Juliette Gréco, Mademoiselle K, Bruno Joubrel, Paris, Honoré-Champion, 2011.

Schaeffer, Jean-Marie, Pourquoi la fiction ?, Paris, Seuil, 1999.

Szendy, Peter, Tubes. La philosophie dans le juke-box, Paris, Les Éditions de Minuit, 2008.

Zumthor, Paul, Introduction à la poésie orale, Paris, Seuil, 1983.

\section{NOTES}

1. On se souvient de la célèbre altercation entre Serge Gainsbourg et Guy Béart dans Apostrophes à propos du statut de la chanson comme 'art mineur'. En ligne: http://www.ina.fr/video/ I05057091

2. Le SNEP, Syndicat National de l'Édition Phonographique, offre des listes de ventes et de diffusion à partir de l'année 2001: http://www.snepmusique.com/tops-annuel/top-albumsfusionnes/

3. Une visite au site du Centre National du Patrimoine de la Chanson (Hall de la chanson) montre bien l'hétérogénéité des artistes présentés et l'absence notoire de toute définition du terme 'chanson' : http://www.lehall.com/a-propos/presentation-du-hall 
4. Minoritaires en raison d'une trop grande exclusivité formelle et/ou thématique ou d'une diffusion restreinte volontaire ou subie.

5. Nous laissons de côté les usages du terme en poésie ou ceux antérieurs aux processus d'enregistrement sonore.

6. Aujourd'hui, le terme 'variété' étant relativement peu utilisé dans la langue courante, l'opposition se ferait d'avantage avec d'autres catégories telles que la 'pop', le 'rock' ou l' 'électro', entre autres. Toutefois, les concepts de chanson et de variété restent valables comme l'atteste l'existence, par exemple, le Centre National de la chanson, les variétés et le jazz, créé en 2002, ainsi que leur inclusion dans les enquêtes sur les pratiques culturelles des Français (Donnat 2009).

7. Sur l'éclectisme et l'omnivorité, voir Peterson 2004.

8. Coulangeon (2010) considère que l'éclectisme n'abolit pas les différences sociales en matière de stratification des goûts culturels. Ainsi, les 'omnivores' appartiendraient aux classes supérieures alors que les classes inférieures seraient quant à elles 'univores'.

9. Plus des deux tiers des Français continuaient à avoir un contact quotidien avec la radio en 2008. (Donnat 2009 : 4).

10. La catégorie utilisée par le Ministère est précisément celle de 'chanson ou variété française'. Les données pour l'enquête 2008 sont disponibles à l'adresse suivante: http:// www.pratiquesculturelles.culture.gouv.fr/doc/tableau/chap5/V-3-3-Q47.pdf

Les données pour l'enquête 2015 sont disponibles dans 'Médias et industries culturelles', Chiffres clés, statistiques de la culture et de la communication 2016, Paris, Ministère de la Culture - DEPS, 'Chiffres clés statistiques de la culture', 2016.

11. L'expression 'chanson française' a été déclinée comme 'nouvelle chanson française' (Looseley 2013a: 72), catégorie où s'inscrivaient des artistes stylistiquement éloignés du modèle BrelBrassens-Ferré comme Jean-Jacques Goldman ou Renaud dans les années 1970. La critique musicale a ensuite utilisé d'autres formules comme 'la nouvelle scène française' pour désigner des artistes variés allant de Dominique A à Jeanne Cherhal en passant par Arthur H, Manu Chao, Benjamin Biolay ou Camille.

12. Cette centralité du logos est caractéristique de la culture française 'officielle' ou 'élevée'.

13. Dans l'ère numérique, le parallélisme s'établit entre les mp3 et mp4, le streaming et l'ebook.

14. Sur les types de répétition en musique populaire, voir Middleton 2006.

15. 'Il', pronom personnel masculin, désigne évidemment les auditeurs des deux genres. Nous n'utilisons pas systématiquement les deux pronoms par souci d'économie linguistique.

16. La bibliographie sur ce sujet est très abondante. Voir, par exemple Griffiths 2003, Astor 2010, Marc 2011, Frith 1987.

17. Plusieurs versions sont disponibles sur Internet, notamment celle-ci, où Aznavour se livre à un exercice de dramatisation remarquable : https://www.youtube.com/watch ?v =DgwFEd_0bYU 18. Le clip officiel est accessible sur : https://www.youtube.com/watch ?v =h5EofwRzit0 19. Sur l'importance de la langue et la culture dans la réception des musiques populaires, voir Marc 2013.

20. ' $Y$ 'a de la joie' contient aussi des traces de narration : la scène du boulanger, celle de la Tour Eiffel qui se promène, puis, le réveil du songe. Toutefois, le tout se déroule en un instant, sans qu'aucun récit n'y soit véritablement développé.

21. Frith considère que toute chanson met en scène - puisqu'il y a certes une représentation -, de façon implicite ou explicite, une narration, avec au moins un personnage principal, le 'je' lyrique, un cadre fictionnel, et le récit de situations et/ou d'évènements présents ou passés (Frith 1996 : 169). Bien que cette affirmation soit juste d'un point de vue général, une analyse des textes permet de retrouver des fonctions 'expressives' / 'poétiques' différentes, à dominante narrative, émotionnelle, ludique, etc., qui peuvent être assimilées aux fonctions communicationnelles. Sur ce sujet, voir Marc 2011. 
22. Le caractère allusif et fragmentaire est consubstantiel aux récits posés dans les chansons. 'Brandt Rhapsody', de Benjamin Biolay et Jeanne Cherhal (2012), en serait un exemple notoire et récent : les paroles racontent l'histoire d'amour d'un couple 'actuel' du début jusqu'à sa fin, à partir des petits messages que s'adressent les deux protagonistes : https://www.youtube.com/ watch ? $\mathrm{v}=$ _mdhpDc4zvM L'absence de caractérisation - chacun d'entre nous pourrait ou aurait pu être à la place des personnages - favorise l'identification et la fabulation individuelle et individualisante des situations générales posées dans les récits-chansons.

23. L'adjectif 'majoritaire' viendrait ici remplacer l'adjectif 'populaire' désignant le 'plus grand nombre'.

24. Le concept de classes moyennes est controversé sur le plan politique et académique. Nous retenons ici la définition proposée par l'observatoire des inégalités qui situent ces classes entre les $30 \%$ plus pauvres et les $20 \%$ plus riches en ce qui concerne le niveau de revenus, correspondant donc à $50 \%$ de la population : http://www.inegalites.fr/spip.php?article1015

25. Sur le plaisir musical, voir 'Le plaisir musical' ,Études 9/2003 (Tome 399), p. 235-249

URL : www.cairn.info/revue-etudes-2003-9-page-235.htm.

\section{ABSTRACTS}

La chanson a été l'un des premiers objets culturels à avoir été théorisé comme 'art moyen' (Bourdieu 1979) et se situe au cœur du débat entre la culture populaire et la culture élevée en France (Looseley 2013a). Cet article vise précisément à caractériser la chanson française comme l'un des objets privilégiés de la culture moyenne, une catégorie esthétique et sociologique nouvelle qui, à notre sens, dépasse le binarisme traditionnel entre culture légitime et culture populaire. Pour ce faire, en adoptant une perspective esthétique, nous réfléchirons premièrement au concept de chanson française et à son évolution dans ses spécificités par rapport aux autres formes de musiques populaires actuelles. Deuxièmement, nous interrogerons le rôle des mécanismes expressifs - concision, brièveté, répétition, réitération, ellipse... - et notamment narratifs de la chanson comme facteurs clé des plaisirs multiples qu'elle peut susciter auprès d'un public large et socialement hétérogène. Ainsi, cette analyse immanente de la chanson nous permettra de réfléchir aux nouveaux rapports entre l'esthétique des objets culturels et leurs moyens de création, de diffusion et de consommation dans le contexte français contemporain.

\section{INDEX}

Mots-clés: chanson française, musiques populaires, musiques actuelles, culture populaire, culture de masse, culture moyenne, microfiction, narrativité, plaisir esthétique.

\section{AUTHOR}

\section{ISABELLE MARC}

Universidad Complutense, Madrid 
Isabelle Marc est maître de conférences au département d'Études françaises de l'Université Complutense de Madrid. Elle s'intéresse à la culture populaire française en général et aux musiques actuelles en particulier. Dans ce domaine, elle a travaillé sur la chanson et sur le rap et sur les rapports entre esthétique et identité culturelle, notamment chez des artistes tels que Georges Brassens, Charles Aznavour ou Dominique A. Sa recherche porte aussi sur les dynamiques transculturelles et la traduction et sur les politiques publiques de la culture en Europe. Son dernier livre, The Singer Songwriter in Europe : Paradigms, Politics and Place, coédité avec Stuart Green, est paru chez Routledge au printemps 2016. Elle codirige l'European Popular Musics Research Group à l'Université de Leeds et elle dirige la revue Thélème. Revista Complutense de Estudios Franceses. 